\title{
ANALISIS SITIRAN ARTIKEL JURNAL LUAR NEGERI PADA LAPORAN PENELITIAN DI LEMBAGA PENELITIAN DAN PENGABDIAN KEPADA MASYARAKAT UGM YANG DIBIAYAI BADAN LITBANG PERTANIAN DEPARTEMEN PERTANIAN TAHUN 2007
}

\author{
Sri Junandi* dan Sri Rochyanti Zulaikha**
}

\begin{abstract}
The study aims: (1) to discover the foreign journal referred by the research reports at Research and Community Services Gadjah Mada University (UGM) funded by the Agricultural Research and Development Department of Agriculture in 2007, (2) to know the percentage of use of the subscribed foreign journal by Library Faculty of Agrocomplex in UGM although Gadjah Mada University Library of the research reports at the Institute for Research and Community Services UGM funded by the Agricultural Research and Development Department of Agriculture in 2007, (3) to know the relevancy and use of foreign journal by the research reports at the Institute for Research and Community Services UGM funded by the Agricultural Research and Development Department of Agriculture in 2007, (4) to know the currency of the foreign journal referred by the research reports at the Institute for Research and Community Services GMU funded by the Agricultural Research and Development Department of Agriculture in 2007.

This study is a descriptive research, with the research reports at the Institute for Research and Community Services UGM funded by the Agricultural Research and Development Department of Agriculture in 2007 as a subject, and the foreign journals referred in the research reports as an object. Documentation and interview are used as methods of collecting data, and citation analysis as an data analysis.

The results of study: (1) There are 103 titles of foreign journal cited in the research reports at the Institute for Research and Community Services UGM funded by the Agricultural Research and Development Department of Agriculture in 2007, including 35 titles of the journal subscribed by Library the Faculty of Agrocomplex in UGM although Library of Gadjah Mada University, (2) The frequence of the citation of the 35 titles was that : Applied and Environmental Microbiology by 14 times (6,51\%), Postharvest Biology and Technology and Trans of the ASAE by 12 (5,55\%), J. of Food Engineering by 10 (4,65\%), J. of Food Science by 10 (3,72\%), Plant and Soil by 8 (3,26\%), J. of Agriculture Eng. Research by 6 (2,79\%), Bioresource Tech. by 5 (2,33\%), Food Tech. and J. of Dairy Science by 4 respectively (1,86\%), Intern. J. of Food Microbiology, J. Animal Science, J. of Biomass and Bioenergy, J. of Stored Product Research, and Solar Energy by 3 respectively $(1,40 \%)$, Food Chemistry, J. Meat Science, J. of Bioscience and Bioengineering, and Soil Science Society of America Journal by each 2 (0,93\%), Agriculture Ecosystems \& Environment, Agricultural Systems, Agronomy J., Biosystems Engi., Biotechnology Letters, Cell, Computers and Electronics in Agricultural, Crop Science, Environmental and Experimental Botany, Food Control, Hort Science, Intern. Dairy J., J. of Food Microbiology, Soil Biology and Biochemistry, Trends in Food Science \& Technology, and Trends in Plant Science by 1 each $(0,47 \%)$. (3) There are also a relevancy between the scientific articles and the foreign journal in the research reports at the Institute for Research and Community Services UGM funded by the Agricultural Research and Development Department of Agriculture in 2007, (4) The foreign journal subscribed by Library the Faculty of Agrocomplex in UGM was included was included in a current category $60.47 \%$ or equal to 130 citation, not current category $40.01 \%$ or equal to 85 citation, and more than 30 years $6,05 \%$ or equal to 13 citation.
\end{abstract}

(Keywords: use of journals, citation analysis)

* Pustakawan UGM

** Dosen UIN Sunan Kalijaga Yogyakarta

\section{PENDAHULUAN}

Kegiatan penelitian bertujuan untuk menghasilkan temuan-temuan baru (inovasi) yang diharapkan dapat meningkatkan kualitas dan produktivitas suatu komoditas. Untuk itu dalam menyusun rencana penelitian para peneliti membutuhkan dukungan berbagai macam sumber literatur yang relevan dengan bidang yang ditelitinya, baik dari literatur primer maupun dari literatur sekunder yang dihasilkan oleh peneliti lain sebagai data untuk memperoleh peluang dalam upaya menghasilkan temuan baru. Untuk menganalisa validitas dan manfaat hasil temuannya digunakan pula bahan pustaka sebagai bahan rujukan. Sebelum merujuk suatu artikel lebih dahulu perlu dianalisis kebenaran, tingkat kepercayaan, dan relevansi artikel tersebut. Penelitipun perlu mengutip dengan lengkap identitas sumber yang digunakan agar peneliti lain dapat menelusuri kembali bahan yang dirujuk.

Penulisan karya ilmiah tidak dapat melepaskan 
diri dari keharusan menggunakan berbagai sumber literatur bahan pustaka sebagai kutipan atau sitiran. Bahan pustaka itu digunakan untuk mendukung uraian penulisan, analisa atau sekurang-kurangnya dirangkaikan dengan buah pikiran peneliti menjadi suatu bangunan uraian teoritis. Biasanya sumber literatur yang dikutip atau disitir dicantumkan pada daftar pustaka/daftar referensi setiap karya ilmiah atau dalam suatu terbitan. Sitiran digunakan peneliti sebagai sandaran ilmiah untuk mengurangi subyektivitas sehingga tingkat obyektivitasnya tinggi dan meningkatkan kualitas karya ilmiahnya.

Untuk mengetahui jenis dan sumber literatur yang dibutuhkan para peneliti dapat dilakukan dengan suatu kegiatan analisis tentang kebutuhan. Salah satu bentuk analisis yang dilakukan untuk mengetahui kebutuhan para peng-guna (peneliti) adalah dengan melakukan analisis sitiran pada setiap tulisan hasil penelitian yang digunakan sebagai bahan rujukan atau daftar pustaka/referensi.

Dalam kajian informasi terhadap daftar kepustakaan salah satunya dikenal dengan analisis sitiran (citation analysis). Analisis sitiran digunakan untuk mengu-kur pengaruh intelektual keilmuan dari pengarang yang disitir, karena beberapa studi sitiran literatur digunakan untuk mengetahui karakteristik komunikasi ilmu pengetahuan dan banyak aspek kualitatif dari penelitian dan publikasi. Kajian tentang pengutipan ini biasa ada pembahasan tentang bagaimana sebuah dokumen dikutip di dokumen lain karena dokumen yang dikutip itu menyediakan informasi yang relevan terhadap riset yang sedang ditulis di dokumen yang mengutip, misalnya dalam hal meto-de, landasan pemikiran, dan sebagainya. Pengutipan tidak perlu menyeluruh. Jika kita asumsikan bahwa semua kutipan bersifat serupa dalam hal sumbangannya kepada artikel pengutip, maka ada beberapa kecenderungan yang dapat diperoleh:

1. Semakin sering sebuah dokumen dikutip, maka semakin besar dokumen itu memberi kontribusi informasi, dan semakin besar pengaruhnya pada penelitian yang sedang dilaporkan di dalam dokumen pengutip. Ukuran dari pengaruh atau dampak (impact) ini adalah jumlah pengutipan.

2. Berapa kali sebuah dokumen dikutip dalam satu rentang waktu tertentu menunjukkan berapa banyak informasi di dalam dokumen tersebut berguna untuk sebuah riset. Jika frekuensinya menurun, maka dokumen tersebut semakin tidak relevan, sampai akhirnya menjadi usang (obsolete).
Jika dua dokumen bersama-sama dikutip oleh dokumen ketiga, maka kedua dokumen tersebut bersama-sama memberi sumbangan. Semakin sering dua dokumen dikutip bersama (co-cited), maka semakin dekat hubungan kedua dokumen tersebut.

Rumusan masalah dalam peneli-tian ini adalah:

a. Apa sajakah jurnal terbitan luar negeri yang dimanfaatkan dalam laporan penelitian?

b. Berapa persentase pemanfaatan masing-masing jurnal terbitan luar negeri yang pernah dilanggan dalam laporan penelitian?

c. Apakah ada kesesuian antara subjek judul penelitian dengan judul artikel yang disitir pada jurnal terbitan luar negeri yang pernah dilanggan dalam laporan penelitian, dan apa manfaatnya dalam laporan penelitian yang menyitirnya?

d. Bagaimana kemutakhiran jurnal terbitan luar negeri yang dimanfaatkan dalam laporan penelitian?

Ruang lingkup penelitian ini dibatasi pada laporan penelitian di LPPM UGM yang dibiayai Badan Litbang Pertanian Departemen Pertanian Tahun 2007. Dengan demikian hasil penelitian hanya memberi gambaran terbatas pada pemanfaatan jurnal terbitan luar negeri (sumber tercetak maupun non tercetak) dan kesesuaian antara subjek judul penelitian dengan judul artikel jurnal yang disitir, serta manfaatnya dalam laporan penelitian yang merujuk, berdasarkan pencantumannya pada daftar pustaka laporan.

Asumsi dasar penelitian ini, adalah bahwa semua jurnal terbitan luar negeri yang dimanfaatkan dalam laporan penelitian benar-benar dimanfaatkan oleh peneliti. Pengertian "dimanfaatkan" maksudnya adalah bahwa jurnal terbitan luar negeri yang disitir dan tercantum dalam daftar pustaka laporan penelitian dimanfaatkan dalam pelaksanaan penelitian. Karena pada dasarnya laporan penelitian merupakan hasil penelitian dari staf pengajar dari Fakultas Agrokomplek UGM khususnya atau peneliti bidang ilmu pertanian pada umumnya.

\section{Fungsi Jurnal dalam Penelitian}

Sesuai dengan Keputusan Ketua Lembaga Ilmu Pengetahuan Indonesia (LIPI) No.81/Kep/H.10/1983 tentang Tata Tertib Publikasi, jurnal adalah maja-lah yang memuat informasi mengenai hasil kegiatan di bidang ilmu penge-tahuan dan teknologi. Di dalam majalah ini berisi kumpulan pengetahuan baru, pengamatan empiris dan pengembangan gagasan atau usulan. Juga dijelaskan bahwa publikasi ini berfungsi sebagai media komunikasi yang sangat penting dalam 
ilmu pengetahuan karena memuat informasi terbaru. Bagi para ilmuwan, media ini dapat dipergunakan sebagai sarana untuk mengikuti perkembangan ilmu pengetahuan dan teknologi dalam bidangnya, dan sekaligus sebagai wadah bagi mereka untuk melaporkan hasil penemuan serta buah pikirannya. Sementara itu menurut Sulistyo-Basuki (2002), jurnal merupakan: (a) media paling penting dalam komunikasi ilmiah, (b) merupakan pengetahuan publik, dan (c) arsip umum yang dapat dibaca oleh siapa saja.

Ilmu pengetahuan berkembang pesat sejak diketemukannya mesin cetak sebagai sarana pengganda hasil informasi terekam. Dampak dari mesin cetak adalah meningkatnya jumlah literatur ilmiah dalam berbagai macam disiplin ilmu pengetahuan. Peningkatan kuantitas literatur ilmiah serta kemudahan memperoleh informasi sangat menunjang perkembangan ilmu pengetahuan. Ilmu pengetahuan terus meningkatkan produktivitas ilmuwan dalam melakukan penelitian, percobaan dan inovasi. Meningkatnya produktivitas karya ilmiah yang dihasilkan ilmuwan akan mendorong terbitnya media komunikasi ilmiah yang mengko-munikasikan hasil kegiatan ilmiah, dari seorang ilmuwan dengan ilmuwan lain pada masanya maupun masa sebelum dan sesudahnya. Media komunikasi yang dimaksud dapat berupa buku atau majalah ilmiah.

Peningkatan intensitas komuni-kasi ilmiah dan perkembangan ilmu pengetahuan, meningkatkan kerjasama antar ilmuwan dalam menghasilkan karya sama. Dalam komunikasi ilmiah, karya sama antar lebih dari satu orang dan/atau lembaga untuk menghasilkan karya sama disebut kolaborasi. Kajian kolaborasi merupakan salah satu dari metode bibliometrika, yang bertujuan memberikan gambaran tentang cara mengukur dan menganalissa proses komunikasi terekam.

Perguruan tinggi berperan penting dalam menyebarkan informasi karena sebuah komunikasi informasi merupakan hal mendasar bagi terselenggaranya sebuah hubungan positif yang diharapkan. Hubungan antara peneliti dengan pihak lain; teman sejawat, mahasiswa, orang yang memanfaatkan penelitian. Karena informasi yang digunakan dengan sebaik-baiknya akan mempersatukan masyarakat. Komunikasi informasi harus dikelola dengan baik, karena dalam proses komunikasi terdapat gangguan yang apabila tidak dikelola dengan baik akan menim-bulkan sesuatu arah komunikasi yang salah.
Komunikasi informasi pada perguruan tinggi yang dilakukan, merupakan serangkaian komunikasi ilmiah. Komunikasi ilmiah adalah sebuah sistem di mana penelitian dan kegiatan ilmiah lain yang dilakukan, ditulis, dievaluasi kualitasnya, disebarkan kepada komunitas ilmiah lain, dan dipertahankan untuk kepentingan masa yang akan datang. Komunikasi ilmiah meliputi komunikasi formal, seperti penerbitan jurnal-jurnal ilmiah; dan komunikasi informal seperti penggunaan media elektronik, penyelenggaraan seminar-seminar.

Komunikasi ilmiah formal lazimnya dilakukan dengan melalui media-media penerbitan berkala, seperti jurnal ilmiah. Garvey, dalam Communication the Essense of Science, Pergamon Press, 1989 (Darmono, 1996:3) menyatakan bahwa komunikasi ilmiah melalui jurnal ilmiah merupakan hal yang amat penting dalam pengembangan ilmu pengetahuan. Melalui jurnal ilmiah, temuan baru dari peneliti dan ilmuwan dikomunikasikan ke masyarakat, guna mendapat tanggapan, dikembangkan dan disempurnakan oleh ilmuwan lain, sehingga kesempurnaan dan kebenaran ilmunya menjadi lebih baik. Jika ditarik lebih jauh, kehadiran berbagai jurnal ilmiah dalam masyarakat akademik juga merupakan investasi jang-ka panjang untuk memacu meningkatkan sumber daya manusia. Setiap penerbitan jurnal mempunyai kekuatan ganda, yaitu sebagai dokumentasi IPTEK dan sekaligus sarana penyebarannya.

Menurut Sulistyo-Basuki (1995: 35-36) sebagai sebuah sistem komunikasi, maka komunikasi ilmiah formal memiliki keuntungan sebagai berikut:

1. Komunikasi formal bersifat terbuka sehingga kehadirannya lebih besar;

2. Penyebaran informasi relatif lebih luas dan lebih murah daripada komunikasi informal;

3. Informasi yang disimpan melalui ko-munikasi formal lebih permanen, menjadi "arsip umum" dan lebih mudah ditemukan;

4. Informasi yang disebarkan sudah melalui pemeriksaan wasit majalah, karenanya sudah disesuaikan dengan standar disiplin ilmu yang bersang-kutan. Demikian pula dengan cara penyajiannya termasuk penulisan arti dan daftar kepustakaan, sudah disesuaikan dengan pedoman yang lazim berlaku untuk pembaca dari kalangan tertentu;

5. Komunikasi formal cenderung mengarah pada kepentingan pembaca luas. 
Sedangkan kerugian komunikasi formal adalah seperti:

1. Usia informasi yang disebarkan melalúi komunikasi formal umumnya lebih tua daripada informasi yang disebarkan melalui komunikasi info-mal. Hal ini terjadi karena frekuensi penerbitan majalah tidak sama, ada-nya waktu tunggu untuk diterbitkan, dan redaksi harus menunggu naskah yang masuk;

2. Seringkali terjadi pengulangan inti makalah walaupun judulnya berbeda dan majalah yang memuatnya pun berlainan.

Artikel dalam jurnal pada umumnya berupa hasilhasil penelitian bidang-bidang yang lebih spesifik atau khusus. Sebagian besar publikasi jenis ini diterbitkan oleh lembaga pendidikan maupun lembaga penelitian, dan akhir-akhir ini penerbit komersial juga telah banyak yang mengelolanya. Agar kualitas tetap terjaga dengan baik, maka terbitan ini biasanya mempunyai editor atau kelompok orang yang memang ahli di bidangnya (Saleh \& Toha, 1996:11).

\section{Analisis Sitíran}

Analisis sitiran adalah kajian terhadap sejumlah sitiran atau rujukan yang terdapat dalam karya tulis ilmiah tertentu (Zulaikha, 2002:41). Sedangkan menurut Hartinah (2002) analisis sitiran adalah penyelidikan melalui data sitiran dari suatu dokumen, baik dokumen yang disitir maupun dokumen yang menyitir. Adapun hal-hal yang diselidiki antara lain: pengarang, subjek, tahun terbit, dan sumber dokumen (jurnal, buku, dan jenis lain). Menurut Sulistyo-Basuki (1994: 177), analisis sitiran adalah analisis pada kepustakaan. Pada awalnya kajian berupa frekuensi sitiran, bahasa, tahun, jenis terbitan, dan pada saat ini berkembang pada kajian terhadap hubungan antara satu majalah dengan majalah lainnya, kajian terhadap ukuran sentralitas antara satu majalah dengan majalah lain, penelitian paro hidup bidang ilmu serta jaringan yang terbentuk akibat sitiran.

Beberapa alasan mengapa para ilmuwan selalu menyitir berbagai macam literatur dalam rangka penulisan karya mereka. Garfield (dalam Hartinah, 2002) mengemukakan bahwa seseorang penulis menyitir penulis lain karena:

1. Memberikan penghormatan kepada penulis atau karya di bidangnya.

2. Mengidentifikasi metodologi atau pendekatan teori.

3. Memberi latar belakang atau bacaan bagi mereka yang ingin mengetahui lebih lanjut topik yang sudah ditulis.

4. Mengoreksi karya sendiri atau karya orang lain.

5. Memberikan kritik terhadap karya yang telah terbit sebelumnya.

6. Memperkuat klaim suatu temuan.

7. Sebagai panduan bagi penulis lain yang akan mendalami topik tulisan yang disitir.

Sedangkan menurut Sulistyo-Basuki (1994:176177), seorang peneliti yang menyitir karya orang lain dan mencantumkannya pada daftar pustaka, bertujuan untuk:

1. Memberikan penghargaan terhadap karya sebelumnya.

2. Memberikan penghargaan pada karya yang berkaitan.

3. Mengidentifikasi metodologi, angka dan sebagainya.

4. Memberikan bahan bacaan sebagai latar belakang.

5. Mengoreksi karya orang lain.

6. Mengoreksi karya sendiri.

7. Mengkritik karya sebelumnya.

8. Mendukung klaim sebuah penemuan.

9. Memberitahu peneliti tentang karya yang akan terbit.

10. Memberikan arahan pada karya yang tidak tersebar, tidak tercakup dalam majalah indeks, atau karya yang tidak pernah dirujuk oleh pengarang lain.

11. Memberi otensifikasi tentang data dan kelompok fakta.

12. Mengidentifikasi publikasi asli tem-pat sebuah ide atau gagasan dibahas.

13. Menyangkal klaim yang diajukan oleh pengarang lain.

14. Mengidentifikasi publikasi orisinal yang memeriksa sebuah istilah, seperti Paretos Law, Friedel-Crafy Reaction.

\section{Kemutakhiran Literatur}

Kemutakhiran informasi untuk setiap bidang ilmu berbeda. Namun yang sering menjadi masalah adalah tidak semua jurnal tercetak dapat segera dimanfaatkan oleh pengguna setelah diterbitkan, kecuali jika perpustakaan melanggan sendiri jurnal tersebut. Setelah berada di perpustakaan jurnal baru harus melalui beberapa tahapan pengolahan. Selanjutnya setelah berada di ruang layanan, pengguna perlu 
menelusurnya terlebih dahulu melalui indeks, katalog atau sarana referensi lainnya untuk dapat memanfaatkannya.

Seiring dengan kemajuan teknologi informasi dan komunikasi maka jarak, ruang, dan waktu menjadi hampir tidak ada batasan. Pola perilaku pengguna perpustakaan dalam mencari informasi perlu mengikuti kemajuan/perubahan tersebut dan perpustakaan harus setiap saat jika diperlukan. Untuk mengikuti perubahan tersebut maka perpustakaan harus terhubung ke jaringan internet karena banyak informasi yang dapat dicari di internet, salah satunya adalah jurnal elektronis.

Ketersediaan informasi mutakhir sangat dibutuhkan oleh peneliti untuk mendukung kegiatan penelitian. Dibandingkan dengan buku/monograf, jurnal ilmiah memuat informasi yang lebih mutakhir karena berisi artikel-artikel hasil penelitian terbaru dan aktual. Pembanding penelitian mestinya lebih mutakhir sehingga peneliti seyogianya menyitir artikel jurnal terbaru dengan lingkup bidangnya.

Pada dasarnya kemutakhiran literatur yang dirujuk dalam suatu karya tulis ilmiah mencerminkan kekinian (actuality) informasi dari karya tulis tersebut (Hermanto, 2004:1). Menurut Instrumen Evaluasi untuk Akreditasi Berkala Ilmiah, 2001, yang dikeluarkan oleh Direktorat Pembinaan Penelitian dan Pengabdian pada Masyarakat, Direktorat Jenderal Pendidikan Tinggi (2001), diisyaratkan bahwa kemutakhiran referensi (pustaka acuan) merupakan salah satu aspek substansial yang dimulai dalam pengakreditasian jurnal ilmiah. Dalam instrumen ini ditegaskan bahwa kemutakhiran referensi tersebut dengan melihat proporsi terbitan sepuluh tahun terakhir.

Meskipun kualitas sebuah karya ilmiah atau penelitian tidak terkait langsung dengan kemutakhiran literatur yang dirujuk, namun literatur-literatur terbaru yang digunakan sebagai rujukan diharapkan akan membuka cakrawala baru dalam pembahasan hasil penelitian. Dengan demikian penggunaan literatur yang sudah tidak mutakhir (out of date) sebagai rujukan dapat diterima sepanjang data atau informasi yang dimiliki relevan dengan topik tersebut, atau belum ada literatur baru yang lebih baik atau lebih lengkap dari literatur tersebut (Hermanto, 2004:3).

Menurut Milkkailov (dalam Herlina, 1995:36), penggunaan literatur yang relatif tidak mutakhir sebagai rujukan dikarenakan adanya kekhususan informasi, misalnya mengenai publikasi orisinil yang menjadi syarat konsep atau ide serta metodologi.
Berdasarkan uraian di atas dapat disimpulkan bahwa kemutakhiran informasi tidak menjadi syarat mutlak seorang peneliti dalam merujuk informasi, sepanjang informasi yang dirujuk sesuai atau relevan dengan subjek yang merujuk, meskipun informasi tersebut tidak muta-khir dan belum ada informasi yang baru dan lengkap dari literatur tersebut.

Dalam penelitian ini sebagai pedoman mengukur kemutakhiran informasi digunakan Instrumen Evaluasi untuk Akreditasi Berkala Ilmiah yang menegaskan bahwa kemutakhiran referensi dengan melihat proporsi terbitan sepuluh tahun terakhir.

\section{METODE PENELITIAN}

Penelitian yang dilaksanakan ada-lah penelitian deskriptif, dengan maksud mengetahui jurnal terbitan luar negeri yang dimanfaatkan (disitir), persentase pemanfaatan jurnal terbitan luar negeri pernah dilanggan, dan usia jurnal terbitan luar negeri yang disitir pada laporan penelitian di LPPM UGM yang dibiayai Badan Litbang Pertanian Departemen Pertanian tahun 2007.

Pada penelitian ini ada dua metode pengumpulan data yang dipergunakan, yaitu metode dokumentasi dan metode wawancara. Metode dokumentasi, karena pada penelitian ini data diperoleh dari daftar pustaka atau sitiran dalam artikel ilmiah yang dimuat pada laporan penelitian. Selanjutnya metode wawancara dipergunakan sebagai bahan pendukung check dan recheck terhadap pemanfaatan jurnal terbitan luar negeri.

Selanjutnya langkah-langkah yang dilakukan dalam pengumpulan data adalah sebagai berikut:

a) Mengumpulkan semua laporan penelitian yang dibiayai Balitbang Pertanian Departemen Pertanian di LPPM UGM yang termasuk dalam populasi penelitian sesuai dengan yang dimaksud yaitu tahun 2007.

b) Memeriksa setiap laporan penelitian yang telah dikumpulkan.

c) Memfotokopi halaman judul laporan penelitian dan daftar pustaka.

d) Setelah data terkumpul, selanjutnya dibuatkan lembar kerja dalam bentuk tabel dengan menggunakan Microsoft Excel. Untuk keperluan tersebut dibuat lembar kerja yang memuat lima kolom meliputi: (1) kolom nomor urut, (2) kolom judul jurnal yang disitir, (3) kolom wilayah terbit yang dibagi menjadi dua kolom yaitu luar negeri dan dalam negeri, (4) kolom tahun terbit. 
e) Membuat tabel yang terdiri atas tiga kolom, yaitu (1) kolom nomor urut, (2) kolom judul jurnal terbitan luar negeri, (3) kolom frekuensi disitir, (4) kolom persentase disitir.

f) Membuat tabel yang terdiri atas tiga kolom, meliputi: (1) kolom nomor urut, (2) kolom judul jurnal terbitan luar negeri, (3) kolom tahun terbit

Setelah data terkumpul kemudian penulis melakukan kegiatan analisis data yang terdiri beberapa tahap:

a. Melakukan koreksi terhadap instrumen yang telah diisi pada lembar kerja (Microsoft Excel).

b. Mengelompokkan data jurnal berda-sarkan wilayah terbit jurnal, dan tahun terbit jurnal.

c. Mencatat semua judul jurnal terbitan luar negeri yang tercantum pada daftar pustaka dalam laporan penelitian.

d. Mengelompokkan jurnal terbitan luar negeri berdasarkan judulnya.

e. Tiap kelompok jurnal yang pernah dilanggan Perpustakaan Fakultas Agrokompleks di UGM, masing-masing dijumlahkan.

f. Menentukan peringkat semua kelompok jurnal terbitan luar negeri yang pernah dilanggan. Hasil penentuan peringkat tersebut kemudian dilakukan penghitungan persentase dan disajikan dalam bentuk tabel.

g. Menentukan peringkat tiap kelompok jurnal terbitan luar negeri yang pernah dilanggan.

h. Hasil penentuan peringkat tersebut kemudian dilakukan penghitungan persentase dan disajikan dalam bentuk tabel.

i. Kemudian masing-masing tabel dilakukan analisis secara deskriptif.

j. Merangking semua judul terbitan luar negeri pada poin (d) berdasarkan tahun terbitan untuk mengetahui kemutakhiran jurnal terbitan luar negeri yang disitir dalam laporan penelitian.

k. Kemutakhiran jurnal terbitan luar negeri adalah dengan melihat proporsi sepuluh tahun terakhir jurnal terbitan luar negeri yang disitir dalam laporan penelitian.

Semua perhitungan persentase menggunakan rumus dari Kerlinger (1990:246) sebagai berikut:

Persentase $=$ proporsi $\times 1000$

\section{Keterangan:}

Proporsi merupakan pecahan yang

- Pembilangnya adalah satu di antara dua frekuensi atau lebih.

- Penyebutnya adalah seluruh frekuensi terobservasi.

\section{HASILDAN PEMBAHASAN}

Berdasarkan analisis data yang diperoleh bahwa ada 221 judul jurnal baik terbitan dalam negeri dan luar negeri yang telah dimanfaatkan atau disitir dalam laporan penelitian. Apabila ditinjau dari prosentase wilayah terbitan yaitu jurnal terbitan luar negeri dimanfaatkan atau disitir sebanyak 215 atau $84 \%$ dan jurnal terbitan dalam negeri sebanyak 41 atau $16 \%$.

Selanjutnya dari 256 judul jurnal terbitan luar negeri dipisahkan dan diperoleh bahwa ada 103 judul jurnal terbitan luar negeri yang telah dimanfaatkan atau disitir dalam laporan penelitian.

Berdasarkan analisis data dari 103 judul jurnal yang telah dimanfaatkan dalam penulisan laporan penelitian, ada 35 judul jurnal yang termasuk dalam kategori pernah dilanggan Perpustakaan Fakultas Agrokompleks di UGM maupun UPU Perpustakaan UGM. Hal tersebut menunjukkan bahwa jurnal terbitan luar negeri yang pernah dilanggan telah memberikan manfaat dan kontribusi dalam penulisan laporan penelitian di LPPM UGM yang dibiayai Balitbang Pertanian Departemen Pertanian tahun 2007 sebesar 35 judul $(33,33 \%)$.

\section{Kesesuaian antara Subjek Judul Penelitian dengan Judul Artikel Jurnal Luar Negeri yang Disitir}

Hasil penelitian pemanfaatan jurnal terbitan luar negeri yang pernah dilanggan dalam penulisan laporan penelitian di LPPM UGM yang dibiayai Balitbang Pertanian Departemen Perta-nian tahun 2007, secara keseluruhan menunjukkan adanya relevansi antara subjek judul penelitian dengan judul artikel yang disitir dalam jurnal terbitan luar negeri tersebut. Hal ini diperkuat dengan adanya kesesuaian antara subjek judul penelitian dengan judul artikel rujukan yang disitir. Telaah ke dalam isi artikel diketahui bahwa sebagian besar rujukan tersebut cenderung lebih banyak dimanfaatkan dalam hal pendekatan teori dan diskusi hasil penelitian terutama untuk memperkuat hasil temuannya.

Dari ke tiga puluh lima jurnal terbitan luar negeri, telah dimanfaatkan dalam laporan penelitian sebagian besar sebagai pendukung hasil penelitian (diskusi hasil 
penelitian) dan sebagian kecil sebagai bahan bacaan (pendekatan teori).

Tabel 1

Frekuensi pemanfaatan jurnal terbitan luar negeri yang pernah dilanggan

\begin{tabular}{|c|c|c|c|}
\hline No. & Judul jurnal & $\begin{array}{l}\text { Frekuensi } \\
\text { Disitir }\end{array}$ & $\begin{array}{c}\text { Persentase } \\
(\%)\end{array}$ \\
\hline 1 & $\begin{array}{l}\text { Applied and } \\
\text { Environmental } \\
\text { Microbiology }\end{array}$ & 14 & $6.51 \%$ \\
\hline 2 & $\begin{array}{l}\text { Postharvest Biology } \\
\text { and Technology }\end{array}$ & 12 & $5.58 \%$ \\
\hline 3 & Trans of the ASAE & 12 & $5.58 \%$ \\
\hline 4 & $\begin{array}{l}\text { Journal of Food } \\
\text { Engineering }\end{array}$ & 10 & $4.65 \%$ \\
\hline 5 & $\begin{array}{l}\text { Journal of Food } \\
\text { Science }\end{array}$ & 8 & $3.72 \%$ \\
\hline 6 & Plant and Soil & 7 & $3.26 \%$ \\
\hline 7 & $\begin{array}{l}\text { Journal of Agriculture } \\
\text { Engineering Research }\end{array}$ & 6 & $2.79 \%$ \\
\hline 8 & $\begin{array}{l}\text { Bioresource } \\
\text { Technology }\end{array}$ & 5 & $2.33 \%$ \\
\hline 9 & Food Technology & 4 & $1.86 \%$ \\
\hline 10 & $\begin{array}{l}\text { Journal of Dairy } \\
\text { Science }\end{array}$ & 4 & $1.86 \%$ \\
\hline 11 & $\begin{array}{l}\text { International Journal of } \\
\text { Food Microbiology }\end{array}$ & 3 & $1.40 \%$ \\
\hline 12 & Journal Animal Science & 3 & $1.40 \%$ \\
\hline 13 & ........ & ......... & ........ \\
\hline 14 & $\ldots \ldots \ldots$ & ......... & ........ \\
\hline 15 & ......... & ........ & ........ \\
\hline 16 & ......... & ........ & ......... \\
\hline 17 & ......... & ......... & $\ldots \ldots \ldots$ \\
\hline 35 & Trends in Plant Science & 1 & $0.47 \%$ \\
\hline \multicolumn{2}{|c|}{ Jumlah } & 121 & $56.28 \%$ \\
\hline
\end{tabular}

Sumber Data Primer yang diolah, 2009.

\section{Kemutakhiran Jurnal yang Disitir}

Seperti telah dikemukakan pada landasan teori, bahwa kemutakhiran literatur yang dirujuk dalam suatu karya tulis ilmiah mencerminkan kekinian (actuality) informasi dari karya tulis tersebut (Hermanto, 2002:1). Pada penelitian ini untuk menentukan kemu-takhiran literatur jurnal terbitan luar negeri yang disitir dalam laporan penelitian di LPPM UGM yang dibiayai Balitbang Pertanian Departemen Pertanian tahun 2007, berpedoman pada instrumen Evaluasi untuk Akreditasi Berkala Ilmiah 2001, yang dikeluarkan oleh Direktorat Pembinaan Penelitian dan Pengabdian Masyarakat, Direktorat Jenderal Pendi-dikan Tinggi 2001. Pada pedoman ini salah satu tolok ukur untuk berkala ilmi-ah (jurnal) adalah kemutakhiran bahan pustaka yang dipergunakan sebagai rujukan dan kemutakhiran bahan pustaka yang dipergunakan sebagai rujukan serta kemutakhiran bahan pustaka ini dengan melihat proporsi terbit sepuluh tahun terakhir.

\section{Tabel 2}

Kemutakhiran Jurnal Terbitan Luar Negeri yang Disitir

\begin{tabular}{|c|c|c|c|}
\hline No. & $\begin{array}{c}\text { Kemutakhiran } \\
\text { (Tahun) }\end{array}$ & $\begin{array}{l}\text { Jumlah } \\
\text { Sitiran }\end{array}$ & $\begin{array}{c}\text { Prosentase } \\
(\%)\end{array}$ \\
\hline 1 & & 36 & $16,74 \%$ \\
\hline 2 & $3-4$ & 27 & $12,56 \%$ \\
\hline 3 & $5-6$ & 27 & $12,56 \%$ \\
\hline 4 & $7-8$ & 27 & $12,56 \%$ \\
\hline 5 & $9-10$ & 13 & $6,05 \%$ \\
\hline 6 & $11-15$ & 28 & $13,02 \%$ \\
\hline 7 & $16-20$ & 21 & $9,77 \%$ \\
\hline 8 & $21-25$ & 16 & $7,91 \%$ \\
\hline 9 & $26-30$ & 7 & $3,26 \%$ \\
\hline 10 & $>30$ & 13 & $6,05 \%$ \\
\hline \multicolumn{2}{|r|}{ Jumlah } & 215 & $100 \%$ \\
\hline
\end{tabular}

Sumber Data Primer yang diolah, 2009.

Berdasarkan pedoman tersebut, hasil analisis data diperoleh bahwa ada 103 judul jurnal luar negeri yang telah dimanfaatkan atau disitir dalam laporan penelitian sebanyak 215. Apabila ditinjau dari kemutakhirannya yaitu sebesar $60,47 \%$ jurnal terbitan luar negeri atau setara dengan 130 sitiran termasuk dalam kategori mutakhir (sepuluh tahun terakhir) yang terdiri atas $0 \mathrm{~s} / \mathrm{d} 2$ tahun sebanyak 36 jurnal $(16,74 \%)$, 3 s/d 4 tahun sebanyak 27 jurnal (12,56\%), 5 s/d 6 tahun sebanyak 27 jurnal (12,56\%), 7 s/d 8 tahun sebanyak 27 jurnal $(12,56 \%)$ dan 9 s/d 10 tahun sebanyak 13 jurnal $(6,05 \%)$.

Jurnal terbitan luar negeri sebesar $40,01 \%$ atau setara dengan 85 sitiran termasuk dalam kategori tidak mutakhir (lebih dari sepuluh tahun terakhir) yang terdiri $11 \mathrm{~s} / \mathrm{d} 15$ tahun sebanyak 28 jurnal $(13,02 \%), 16$ s/d 20 tahun sebanyak 21 jurnal (9,77\%), 21 s/d 25 tahun sebanyak 16 jurnal $(7,91 \%), 26$ s/d 30 tahun sebanyak 7 jurnal $(3,26 \%)$ dan lebih 30 tahun sebanyak 13 jurnal $(6,05 \%)$.

\section{Simpulan}

Penelitian yang telah terurai di atas diperoleh beberapa simpulan sebagai berikut:

a. Di dalam laporan penelitian, telah dimanfaatkan jurnal terbitan luar negeri sebanyak 103 judul.

b. Persentase pemanfaatan jurnal luar negeri pada laporan penelitian, peringkat pertama diperoleh 
Applied and Environmental Microbiology dengan perolehan sitiran sebanyak 14 sitiran $(6,51 \%)$. Sedangkan rangking terendah diterima oleh 71 jurnal, dimana masing-masing memperoleh satu kali sitiran $(0,47 \%)$.

c. Terdapat sebanyak 35 jurnal terbitan luar negeri yang telah dimanfaatkan dalam laporan penelitian dan ketigapuluhlima jurnal tersebut, ada kesesuaian antara subjek judul penelitian dengan judul artikel yang disitir dalam laporan penelitian. Jurnal-jurnal terbitan luar negeri yang disitir tersebut sebagian besar dimanfaatkan sebagai pendukung hasil penelitian (diskusi hasil penelitian) dan sebagian kecil sebagai bahan bacaan (pendekatan teori).

Secara deskriptif hasil penelitian menunjukkan bahwa kemutakhiran jurnal terbitan luar negeri yang telah dimanfaatkan dalam laporan penelitian, adalah $60,47 \%$ termasuk kategori mutakhir (sepuluh tahun terakhir) setara dengan 130 sitiran dan $40,01 \%$ tidak termasuk dalam kategori mutakhir (lebih dari sepuluh tahun terakhir) setara dengan 85 sitiran. Disamping itu ada $6,05 \%$ setara 13 sitiran jurnal terbitan luar negeri yang diterbitkan 30 tahun yang lalu atau lebih, meskipun demikian pemanfaatan jurnal tersebut dapat dimaklumi karena (1) adanya kese-suaian antara topik yang disitir dengan yang menyitir, (2) karena kelangkaan topik penelitian, (3) karena adanya kekhususan informasi

\section{DAFTAR PUSTAKA}

American Library Association. ALA's Guide to the Evaluation of Library Collections.

Anonim, 2007. "Undang-Undang Republik Indonesia No. 43 Tahun 2007 Tentang Perpustakaan". Jakarta: Sekretariat Negara.

Budd, J.M. 1990. "Higher Education Li-terature: Characteristic of Cita-tion Patterns", The Journal of Higher Education. Vol. 61 (1):84-97.

Ching, JTY., and Chennupati, KR. 2002. "Collection Evaluation through Citation Analysis Techniques: A Case Study of the Ministry of Education, Singapore", Library Review, Vol. 51 (18/9):398405.

Darmono, 1996. Komunikasi Ilmiah Melalui Jurnal Mengapa Kita Tertinggal?. Dalam http://www.hamline.edu/apakabar/basisdata/199 6/08/02/0050.html, diakses pada tanggal 14 April 2009, pukul 14.05
Direktorat Pembinaan Penelitian dan Pengabdian pada Masyarakat-Ditjen Dikti bekerjasama dengan Lembaga Ilmu Pengetahuan Indonesia, Ikatan Penyunting Indonesia, dan Kantor Menteri Negara Riset dan Teknologi. 2001. Instrumen Evaluasi untuk Akreditasi Berkala Ilmiah (Lampiran). Jakarta.

Hartinah, S. 2002. "Analisis Sitiran (Citation Analysis)". Kumpulan Makalah Kursus Bibliometrika. Depok: Masyarakat Informetrika Indonesia. 20-23 Mei 2002.

Herlina, E. 1995. "Analisis Sitiran Publikasi Hasil Penelitian Pertanian", Jurnal Perpustakaan Pertanian, Vol. IV, (2):33-38.

Hermanto. 2004. "Kajian Kemutakhiran Referensi Artikel Ilmiah pada Beberapa Jurnal Ilmiah Penelitian Pertanian", Jurnal Perpustakaan Pertanian, Vol. 13,(1):1-6.

Kamus Besar Bahasa Indonesia. 1988. Jakarta: Balai Pustaka.

Kerlinger, F.N. 1990. Asas-asas Penelitian Behavioral. Edisi 3. Penerjemah: Landung R. Simatupang. Yogyakarta: Gadjah Mada University Press.

Lasa HS. 1998. Kamus Istilah Perpustakaan. Yogyakarta: Gadjah Mada University Press. .. 2005. Manajemen Perpustakaan. Yogyakarta: Gama Media.

Lembaga Ilmu Pengetahuan Indonesia (LIPI). 1983. Keputusan Ketua LIPI No.81/Kep/H.10/1983 tentang Tata Tertib Publikasi. Jakarta: LIPI.

Rousseau, R. 2002. "Journal Evaluation: Technical and Practical Issues", Library Trends. Vol. 50, Winter (3):418-439.

Saleh, A.R. \& Toha, Y.Y. 1996. Pengelolaan Terbitan Berseri. Jakarta: Universitas Terbuka.

Sastrohamidjojo, H. et.al. 2000. Pedoman Pengelolaan Penelitian di Lembaga Penelitian Universitas Gadjah Mada. Yogyakarta: Gadjah Mada University Press.

Septiyantono, T. 1997. "Kajian Bibliometrika: Manfaat Bagi Ilmu Perpustakaan" Disampaikan dalam Seminar di UPT Perpustakaan UGM tanggal 9 Agustus 1997.

\footnotetext{
-----, 2007. Dasar-dasar Ilmu Perpustakaan dan Informasi, Yogyakarta: Jurusan Ilmu Perpustakaan dan Informasi Fakultas Adab UIN Sunan Kalijaga.
} 
Sulistyo-Basuki. 1994. "Analisis Sitiran, Kositiran dan Pasangan Bibliografis (Citation Analysis, Co-Citation, and Bibliographic Coupling)". Dalam Sosok Pribadi Unik Mastini Hardjoprakosa. Mochtar, K. dkk (Ed). Jakarta: Yayasan Kawedi.

1995. Komunikasi Ilmiah dan Manfaatnya bagi Tenaga Pengajar dan Mahasiswa. Sebuah makalah dalam Seri Pengembangan Perpustakaan: Mempertanyakan Keberadaan Perpustakaan Kita. Semarang: Soegijapranata Catholic University Press.

2002. "Bibliometrika, Sainsmetrika dan Infrometrika". Kumpulan Makalah Kursus Bibliometrika. Depok: Masyarakat Informe-trika Indonesia. 20-23 Mei 2002.
Wikipedia, The Free Encyclopedia. Dalam (http://en.wikipedia.org/ wiki/Editorial board). Diakses 23 Maret 2008.

Zulaikha, S.R. 2002. "Kajian Analisis Sitasi terhadap Skripsi Mahasiswa IAIN Sunan Kalijaga di UPT Perpustakaan UIN Sunan Kalijaga Yogyakarta (Suatu Evaluasi Keterpakaian Koleksi Perpustakaan Ditinjau dari Analisis Sitasi". (Tesis). Yogyakarta: Program Pascasarjana Universitas Gadjah Mada. 